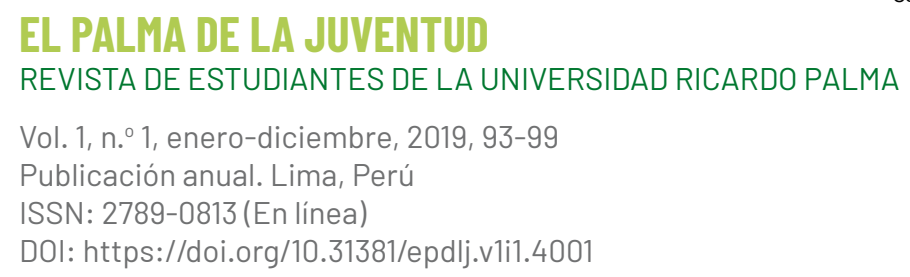

\title{
MEDICINA TRADICIONAL EN LAS TRADICIONES PERUANAS DE RICARDO PALMA'
}

\section{Traditional medicine in the Tradiciones peruanas by Ricardo Palma}

\section{BRIGITH ANABELI BELTRÁN SIMÓN}

Facultad de Medicina Humana, Universidad Ricardo Palma

Lima, Perú

Contacto: 201920262@urp.edu.pe

\section{RESUMEN}

Este artículo analizará las tradiciones «Los polvos de la condesa»y «El abad de Lunahuaná», textos en los que Ricardo Palma informa sobre las antiguas y tradicionales formas naturales de cómo se trataba una enfermedad con las plantas de la quinina, el llantén y la hierba santa.

Palabras clave: Tradiciones peruanas; medicina tradicional; quinina; llantén; hierba santa.

1 Este artículo se elaboró como parte del curso Taller de Comunicación Oral y Escrita I, asignatura dictada por la profesora Vilma Vera Collazos Alarcón en el semestre 2019-II. 


\section{ABSTRACT}

This article will analyze the traditions «Los polvos de la condesa» and «El abad de Lunahuaná», texts where Ricardo Palma explains the ancient and traditional natural ways of how a disease was treated with the quinine, the plantain and the hoja santa or sacred leaf.

Key words: Tradiciones peruanas; traditional medicine; quinine; plantain; sacred leaf.

Recibido: 08/11/2019 Aceptado: 08/12/2019

\section{INTRODUCCIÓN}

Desde que el hombre existe en la tierra ha padecido enfermedades, entonces ¿cómo es que se enfrentó a estas afecciones patológicas? En un inicio, la medicina se basó en el empirismo, doctrina psicológica que afirma cualquier conocimiento mediante la experiencia, teniendo que emplearlo para observar si era favorable o no para la salud, «de ella también son parte principal otros recursos terapéuticos y preventivos, como la ingestión de hierbas eméticas, el masaje, las escarificaciones, el baño, la cauterización e incluso la inoculación antivariólica» (Laín, 1987, p. 7).

Ricardo Palma en su obra Tradiciones peruanas nos ofrece una vista hacia el área de la medicina, todo ello expuesto a través de poéticas e interesantes narraciones que fueron recogidas por vía oral, lo cual ha convertido a sus Tradiciones en una de las más grandes manifestaciones:

Lo demuestra que sea citado con profusión y veneración por muchos historiadores y ensayistas, que sea alabado por críticos y escritores como Juan Valera o Ventura García Calderón, que se le hayan dedicado múltiples estudios - casi ninguno por cierto al tema que me ocupa en 
esta tesis-y que no haya "perulero» instruido que no haya leído sus magníficas Tradiciones (Montiel, 2015, p. 10).

Podemos decir entonces que este excepcional y galardonado personaje contribuyó en gran medida al conocimiento de la historia del Perú apoyándose firmemente en fuentes primarias (vía oral) y añadiendo sus aportes a estas tradiciones, que despertaron en muchos historiadores inspiración y la vocación de sumergirse en las páginas de su obra.

«El abad de Lunahuaná», que integra la novena serie de las Tradiciones peruanas (1874), nos relata que el papa Gregorio XIII tenía una caries maxilar y debido a que no existía mayor conocimiento en la ciencia odontológica llevaba meses postrado hasta que fray Miguel de Carmona (un fraile perulero) trae consigo unas hierbas del Perú: hierba santa y cataplasmas de llantén, a los tres días su santidad Gregorio se encontraba en perfectas condiciones.

La tradición «Los polvos de la condesa», perteneciente a la segunda serie, nos relata que en el año 1631 todo el pueblo se encontraba reunido en la puerta lateral del palacio a la espera de buenas noticias, porque doña Francisca había contraído la fiebre periódica también llamada fiebre terciaria. Entonces llegó el doctor Juan de Vega a la casa del virrey y este le comunicó que solo un milagro podría salvar a su esposa. Días después, un indio enfermo para calmar su sed tomó el agua de un río que se encontraba cerca de un árbol de la quinina y se curó de la fiebre. Esta experiencia llegó a oídos de un jesuita, que le hizo preparados con la quinina, lo que trajo como consecuencia la pronta recuperación de la virreina.

Estas dos tradiciones se encuentran estrechamente relacionadas con la medicina tradicional usada con fines curativos, ya que nos informan sobre las diferentes plantas medicinales empleadas para curaciones específicas. 
Como bien se sabe, en los siglos XVI y XVII la medicina apenas se encontraba en sus inicios y los conocimientos sobre esta ciencia eran escasos, por lo que las personas que se dedicaban a estudiarla eran pocas e inexperimentadas, como se muestra en la tradición «El abad de Lunahuaná»:

El dolor de muelas era rebelde a cataplasmas, emolientes, pediluvios y sangrías, que en aquel siglo la ciencia odontálgica andaba tan en mantillas, que cirujano o barbero alguno de toda la cristiandad no se habría atrevido a emplear lamedor de gatillo mientras hubiese cachete hinchado.

Con el sistema curativo empleado por los galenos de Roma, iba el egregio enfermo en camino de liar el petate. $Y$ lo que al principio fue una bagatela, se iba, por obra de médicos torpes, convirtiendo en gravísimo mal (Palma, 2015, p. 35).

Del fragmento citado, observamos que aquellos que se dedicaban a la medicina en este caso eran los denominados cirujanos-barberos, quienes ejercían la profesión de cirujanos y dentistas al mismo tiempo. Cuando se presentaba una complicación como una inflamación o hinchazón de muelas, no se atrevían a proceder o, en caso contrario, al igual que los galenos de Roma no empleaban los correctos procedimientos, empeorando aún más la situación del paciente.

También observamos otra posición del médico en «Los polvos de la condesa», donde simplemente este da la noticia sin reparo, sin buscar una forma de hacer algo que vaya más allá de lo que ya está establecido como profesional médico:

El doctor Juan de Vega, nativo de Cataluña y recién llegado al Perú, en calidad de médico de la casa del virrey, era una de las lumbreras de la ciencia que enseña a matar por medio de un récipe.

— ¿Y bien, D. Juan? —le interrogó el virrey más con la mirada que con la palabra. 
—Señor, no hay esperanza. Solo un milagro puede salvar a doña Francisca.

Y D. Juan se retiró con aire compungido (Palma, 2014, p. 316).

El conocimiento de la medicina tradicional solo lo tenían algunas personas privilegiadas, manteniendo todo en perfil bajo debido a que la primera impresión que mostraban las personas al descubrir las propiedades medicinales de las plantas era negativa, pues se pensaba que era efecto de la magia negra. Así lo demostró un fundamental estudio etnológico hecho por F. E. Clements, al describir que: «en la interpretación de la enfermedad vigente entre los pueblos primitivos suelen ser distinguidas cinco formas principales: el hechizo nocivo, la infracción de un tabú, la penetración mágica de un objeto en el cuerpo, la posesión por espíritus malignos y la pérdida del alma» (Laín, 1978, p. 8).

En las dos tradiciones se muestra la misma inquietud cuando se trata de hablar sobre la medicina tradicional:

En este conflicto ocurriósele al padre Carmona dirigirse al camarlengo y decirle que, pues Su Santidad se encontraba desahuciado, nada se perdía con permitirle que intentara su curación, empleando hierbas que había traído del Perú, y cuya eficacia entre los naturales de América, para dolencias tales, le constaba. Refirió el camarlengo al Papa la conversación con el perulero, y Su Santidad, como quien se acoge a una última esperanza, mandó entrar en su dormitorio al padre Carmona, y después de obsequiarle una bendición papal, le dijo:

-A ti me encomiendo (Palma, 2015, p. 36).

Ahora bien, vemos que el papa adquiere como última posibilidad para curarse el uso de hierbas, mostrándose un clima de desconfianza por su parte. Además, se le echa la culpa al fraile perulero por las reacciones que tiene su santidad luego de haberle proporcionado hierba santa con leche, cataplasmas de llantén con vinagrillo y 
parches de tabaco bracamoro en las sienes: «sufrió el enfermo náuseas atroces, calambres y sudores, terminando por aletargarse, lo que dio motivo para que los palaciegos se alarmasen, recelando que el fraile perulero hubiera administrado algún tósigo al Pontífice» (Palma, 1964, p. 199).

Esencialmente el llantén es usado porque contiene propiedades que retraen los tejidos y puede producir acciones cicatrizantes, antiinflamatorias y antihemorrágicas, que se usaban, en otro tiempo, en la medicina.

Otro texto en el que puede reconocerse estas relaciones de intertextualidad es «Los polvos de la condesa», donde como se mencionó al principio:

Atacado de fiebres un indio de Loja llamado Pedro de Leyva, bebió para calmar los ardores de la sed del agua de un remanso, en cuyas orillas crecían algunos árboles de quina. Salvado así, hizo la experiencia de dar de beber a otros enfermos del mismo mal cántaros de agua en los que depositaba raíces de cascarilla. Con su descubrimiento vino a Lima y lo comunicó a un jesuita, el que, realizando la feliz curación de la virreina, hizo a la humanidad mayor servicio que el fraile que inventó la pólvora.

Los jesuitas guardaron por algunos años el secreto, y a ellos acudía todo el que era atacado de tercianas. Por eso, durante mucho tiempo, los polvos de la corteza de quina se conocieron con el nombre de polvos de los jesuitas. El doctor Scrivener dice que un médico inglés, Mr. Talbot, curó con la quinina al príncipe de Condé, al delfín, a Colbert y otros personajes, vendiendo el secreto al gobierno francés por una suma considerable y una pensión vitalicia (Palma, 2014, p. 319).

El análisis de este fragmento nos lleva a deducir que cuando se encontraban propiedades curativas de una planta (en este caso la quinina), esta información no se divulgaba, es por ello que se le 
conoció en ese periodo como «los polvos de los jesuitas»; es más, el «médico inglés, Mr. Talbot» se benefició de ello ofreciendo la cura de la enfermedad a cambio de dinero. Por sobre todo esto, las propiedades de la quinina se fueron descubriendo de manera inconsciente en el transcurso de las actividades diarias que ellos realizaban. Así, en homenaje a la condesa que se curó, se le denomina también Cinchona, la cual comprende muchas especies útiles en la medicina, una de ellas es la que cumple el rol de excelente tónico digestivo.

En conclusión, se ha logrado encontrar similitudes en la forma en que se desempeñó la medicina tradicional. En las dos tradiciones de Palma se muestra el poco interés por adquirir mayores conocimientos sobre las plantas medicinales. Si nos referimos al descubrimiento de las propiedades curativas, este fue totalmente inconsciente, a pesar de no haberle dado el enfoque que merecían, las plantas cumplieron un rol fundamental en las vidas de los pobladores, ya que con los pocos avances de la época una enfermedad era cuestión de vida o muerte.

\section{REFERENCIAS}

Laín, P. (1978). Historia de la medicina. Salvat.

Montiel, L. (2015). Médicos y medicina en la obra de Ricardo Palma. Universidad Complutense de Madrid. Facultad de Medicina. https://eprints.ucm.es/44738/1/T39298.pdf

Palma, R. (2014). Los polvos de la condesa. En Tradiciones peruanas. Primera y segunda series (M. Á. Rodríguez Rea, ed.; pp. 315-320). Universidad Ricardo Palma, Editorial Universitaria.

Palma, R. (2015). El abad de Lunahuaná. En Tradiciones peruanas. Novena y décima series (M. Á. Rodríguez Rea, ed.; pp. 35-37). Universidad Ricardo Palma, Editorial Universitaria. 